\title{
Salinity Tolerance in Four Wild Tomato Species using Vegetative Yield-Salinity Response Curves
}

\author{
M.C. Bolarín and F.G. Fernández \\ Centro de Edafología y Biología Aplicada del Segura, Consejo Superior de Investigaciones \\ Científicas, Apartado 195, Murcia, Spain
}

V. Cruz and J. Cuartero

Estación Experimental La Mayora, Consejo Superior de Investigaciones Científicas, Algarrobo. Costa, 29750 Málaga, Spain

Additional index words. Lycopersicon pimpinellifolium, L. peruvianum, L. hirsutum, L. pennellii, nutrient solution, $\mathrm{Na}^{+}$ ion, $\mathrm{Cl}^{-}$ion

\begin{abstract}
The salinity tolerances of 21 accessions belonging to four wild tomato species [Lycopersicon pimpinellifolium (Jusl.) Mill., L. peruvianum (Corr.) D’Arcy, L. hirsutum (L.) Mill., and L. pennellii Humb. Bonpl.) were evaluated using their vegetative yield-salinity response curves at the adult stage, determined by a piecewise-linear response model. The slope (yield decrease per unit salinity increase), salinity response threshold, maximum electrical conductivity without yield reduction $\left(\mathrm{EC}_{0}\right)$, and salinity level for which yield would be zero $\left(\mathrm{EC}_{\mathrm{o}}\right)$ were determined by a nonlinear least-squares inversion method from curves based on the response of leaf and stem dry weights to substrate EC. The genotype PE-2 (L. pimpinellifolium) had the highest salt tolerance, followed by PE-45 (L. pennellii), PE-34, PE-43 (L. hirsutum), and PE-16 (L. peruvianum). The model also was tested replacing substrate salinity levels with leaf $\mathrm{Cl}^{-}$or $\mathrm{Na}^{+}$concentrations. Concentrations of both ions for which vegetative yields were zero $\left(\mathrm{Cl}_{0}\right.$ and $\left.\mathrm{Na}_{0}\right)$ were determined from the response curves. In general, the most tolerant genotypes were those with the highest $\mathrm{Cl}_{\mathrm{o}}$ and $\mathrm{Na}_{\mathrm{o}}$ values, suggesting that the dominant salt-tolerance mechanism is ion accumulation, but there were cases in which salt tolerance was not related to $\mathrm{Cl}_{0}$ and $\mathrm{Na}_{0}$.
\end{abstract}

Investigation of salt tolerance potential Lycopersicon and its closely related wild species was initiated by Lyon (1949), who suggested that salt tolerance might be improved by introgressing genes from Lycopersicon pimpinellifolium to the cultivated tomato. High salt tolerance has been reported for other wild relatives of the cultivated tomato (Dehan and Tal, 1978; Phills et al., 1979; Rush and Epstein, 1976; Tal, 1971). As these wild species (L. cheesmanii, L. peruvianum, L. pennellii, L. hirsutum, etc.) can be crossed with more or less difficulty to the cultivated tomato, they represent potential gene sources of salt tolerance that could be exploited by interspecific hybridization. Wide differences in salinity tolerance have been found between and within wild species (Shannon et al., 1987). Therefore, before beginning a breeding program, it would be useful to screen genotypes suitable as parents for developing salinity-tolerant lines.

Salt tolerance of crop plants usually has been expressed as the yield decrease for a given level of soluble salts in the root medium compared with yields under nonsaline conditions (Bernstein et al., 1974). Maas and Hoffman (1977) expressed salinity tolerance of agricultural crops by two characteristics: salinity threshold (the maximum level of salinity that can be tolerated without loss of yield) and slope. Slope was calculated by linear regression of yield decrease vs. salinity level increase beyond the threshold. Feinerman et al. (1982) proposed a more accurate switching regression method to estimate the coefficients of the piecewise linear response model. Unfortunately, their method was restricted to those data sets that had at least two data points to the left and at least three points to the right of the fitted threshold value. This restriction makes the method less suitable for experiments with relatively few data points than

Received for publication 4 June 1990. This research has been supported by CAICYT (Project no. PA-85/140). The cost of publishing this paper was defrayed in part by the payment of page charges. Under postal regulations, this paper therefore must be hereby marked advertisement solely to indicate this fact. for those with many data points. Further, van Genuchten (1983) used a more general nonlinear least-squares method to simultaneously estimate the three unknown characteristics, maximum yield, slope, and salinity threshold, of the three piecewise linear salt-tolerance response functions. The yield-salinity response model has been applied not only to fruit yield but also to development features, such as height (Anastasio et al., 1987) and vegetative yield (Shannon et al., 1987). However, the substrate salinity level has been expressed in terms of electrical conductivity of the substrate or in terms of leaf concentration of salt stress inductor ions (Bingham et al., 1985).

In our work, the model proposed by van Genuchten (1983) was used to evaluate the salinity tolerance of 21 genotypes belonging to four Lycopersicon wild species and to select those that could be used as parents in breeding programs. Salinity tolerance cannot be assessed by fruit yield since the $L$. peruvianum, L. hirsutum, and L. pennellii entries are not always self-compatible. Therefore, the model was applied to two attributes of vegetative yield; i.e., leaf and stem dry weights vs. substrate salinity levels. The model also has been applied in this work using leaf $\mathrm{Cl}^{-}$and $\mathrm{Na}^{+}$concentrations instead of substrate salinity levels.

\section{Materials and Methods}

The 21 genotypes (Table 1) were chosen because their salinity tolerance had not been evaluated previously and because $L$. pimpinellifolium, L. peruvianum, and L. pennellii had been described as potential sources for salt tolerance (Lyon, 1941; Shannon et al., 1987). L. hirsutum salt tolerance was unknown at the mature stage.

Seeds of the wild species were soaked in $2.7 \%$ (v/v) $\mathrm{NaOCl}$ for $45 \mathrm{~min}$ and rinsed thoroughly with distilled water before germination (Tal and Shannon, 1983). Seeds were germinated

Abbreviations: EC, electrical conductivity; LDW, leaf dry weight; SDW, stem dry weight. 
Table 1. Components of salt tolerance response curves of four wild tomato species calculated on the basis of piecewise linear model.

\begin{tabular}{|c|c|c|c|c|c|c|}
\hline \multirow{2}{*}{$\begin{array}{l}\text { Species } \\
\text { and } \\
\text { accession }\end{array}$} & \multicolumn{3}{|c|}{ Leaf dry wt $(\mathrm{g})$} & \multicolumn{3}{|c|}{ Stem dry wt $(\mathrm{g})$} \\
\hline & $\begin{array}{c}E^{E C_{0}{ }^{2}} \\
\left(\mathrm{~S} \cdot \mathrm{m}^{-1}\right) \\
\end{array}$ & $\begin{array}{c}\mathrm{Cl}_{0} \\
\left(\mathrm{mg}: \mathrm{g}^{-1}\right)\end{array}$ & $\begin{array}{c}\mathrm{Na}_{0} \\
\left(\mathrm{mg} \cdot \mathrm{g}^{-1}\right)\end{array}$ & $\begin{array}{c}\mathrm{EC}_{0} \\
\left(\mathrm{~S} \cdot \mathrm{m}^{-1}\right)\end{array}$ & $\begin{array}{c}\mathrm{Cl}_{0} \\
\left(\mathrm{mg} \cdot \mathrm{g}^{-1}\right)\end{array}$ & $\begin{array}{c}\mathrm{Na}_{0} \\
\left(\mathrm{mg} \cdot \mathrm{g}^{-1}\right)\end{array}$ \\
\hline \multicolumn{7}{|l|}{ L. pim. } \\
\hline PE-2 & 6.72 & 363.5 & 202.5 & 5.76 & 346.2 & 199.1 \\
\hline PE-8 & 2.57 & 104.6 & 64.5 & 2.57 & 97.5 & 61.5 \\
\hline PE-13 & 3.12 & 85.3 & 44.6 & 2.71 & 75.7 & 39.4 \\
\hline PE-14 & 2.56 & 96.9 & 64.5 & 2.85 & 104.0 & 67.2 \\
\hline PE-15 & 2.62 & 84.4 & 55.1 & 2.57 & 83.5 & 54.4 \\
\hline \multicolumn{7}{|l|}{ L. per. } \\
\hline PE-16 & 3.38 & 93.2 & 24.3 & 2.89 & 78.1 & 21.6 \\
\hline PE-18 & 2.19 & 92.8 & 27.2 & 2.46 & 95.7 & 43.8 \\
\hline PE-20 & 1.55 & 37.0 & 18.7 & 2.57 & 107.5 & 35.8 \\
\hline PE-51 & 2.26 & 87.2 & 24.7 & 2.51 & 119.1 & 25.2 \\
\hline PE-52 & 1.63 & 81.4 & $\cdots$ & 1.63 & 94.8 & 26.4 \\
\hline PI-40 & 2.95 & 137.5 & 77.5 & 2.46 & 92.4 & 63.7 \\
\hline PI-48 & 2.42 & 110.9 & 62.1 & 2.36 & 108.0 & 58.9 \\
\hline \multicolumn{7}{|l|}{ L. hir. } \\
\hline PE-34 & 3.55 & 262.1 & 115.0 & 2.56 & 118.5 & 62.7 \\
\hline PE-35 & 2.15 & 49.3 & 31.6 & 2.29 & 47.3 & 30.5 \\
\hline PE-36 & 2.89 & 72.4 & 34.7 & 2.36 & 70.4 & 23.9 \\
\hline PE-37 & 2.97 & 86.9 & 54.0 & 2.21 & 60.9 & 42.5 \\
\hline PE-39 & 2.39 & 48.9 & 26.1 & 2.36 & 55.8 & 33.1 \\
\hline PE-41 & 3.12 & 85.4 & 48.2 & 2.71 & 63.9 & 39.0 \\
\hline PE-43 & 3.43 & 96.7 & 51.4 & 3.43 & 110.1 & 58.2 \\
\hline \multicolumn{7}{|l|}{ L. pen. } \\
\hline PE-45 & 3.15 & 306.1 & 173.0 & 2.62 & 158.5 & 96.5 \\
\hline PE-47 & 2.69 & --. & --. & 2.76 & -- &.- \\
\hline $\operatorname{LSD}_{0.05}$ & 0.38 & 17.5 & 4.3 & 0.32 & 9.9 & 3.5 \\
\hline
\end{tabular}

${ }^{z} \mathrm{EC}_{0}, \mathrm{CL}_{0}$, and $\mathrm{Na}_{\mathrm{o}}=\mathrm{EC}$ of the substrate, and $\mathrm{Cl}-$ and $\mathrm{Na}^{+}$leaf concentrations at which LDW and SDW would reach zero.

${ }^{\prime} L$. pim. $=$ Lycopersicon pimpinellifolium; L. per. $=$ L. peruvianum; L. hir. $=$ L. hirsutum; L. pen. $=$ L. pennellii; PI-40 = PI-126440; PI-48 = PI-126448.

in darkness on filter paper soaked with distilled water, and, after emergence, seedlings were transferred to rock wool as a culture substrate in the greenhouse. Seedlings were irrigated with a nutrient solution containing (in $\mathrm{mM}$ ): $1.72 \mathrm{~K}_{2} \mathrm{SO}_{4}, 5.44 \mathrm{KNO}_{3}$, $3.05 \mathrm{Ca}\left(\mathrm{NO}_{3}\right)_{2}, 0.5 \mathrm{NH}_{4} \mathrm{NO}_{3}, 1.35 \mathrm{HNO}_{3}, 1.81 \mathrm{H}_{3} \mathrm{PO}_{4}$; and (in $\mu \mathrm{M}) 75.1 \mathrm{Fe}$ as diethylene-triamine pentaacetate, $16.70 \mathrm{H}_{3} \mathrm{BO}_{3}$, $1.38 \mathrm{ZnSO}_{4}, 1.10 \mathrm{CuSO}_{4}, 0.52 \mathrm{Na}_{2} \mathrm{MoO}_{4}$, and 16.4 $\mathrm{MnSO}_{4}$.

Control plants were irrigated with the nutrient solution, and treated plants with nutrient solution plus $\mathrm{NaCl}$ at 2,4 , or 8 g.liter ${ }^{-1}$ from the time that plants had five true leaves until the end of experiment. The rock wool substrate underwent rapid salinization until equilibrium of the substrate with the irrigation solution was reached (7 days). The average root-zone ECs were measured on the lixiviated solutions $60 \mathrm{~min}$ after irrigation was started. The EC of the substrate irrigated with nutrient solution was $0.28 \mathrm{~S} \cdot \mathrm{m}^{-1}$ and the ECs of the substrates irrigated with $\mathrm{NaCl}\left(2,4\right.$, and $8 \mathrm{~g} \cdot$ liter $\left.^{-1}\right)$ were $0.63,1.39$, and $2.15 \mathrm{~S} \cdot \mathrm{m}^{-1}$, respectively. The initial $\mathrm{pH}$ values of the nutrient solution and the three saline solutions were $6.9,6.8,6.4$, and 6.4 , respectively, although they were maintained between 6.0 and 6.5 with additions of $\mathrm{H}_{2} \mathrm{SO}_{4}$. Daily mean maxima and minima in the greenhouse were $37 \pm 2 \mathrm{C}$ and $22 \pm 1 \mathrm{C}$, respectively.

The experiment was conducted in three blocks, and in each block, three plants per genotype and treatment were analyzed. The plants were harvested 10 weeks after the beginning of saline treatments. LDW and SDW were determined and leaf samples were taken for chemical analysis for each plant. Leaf tissue was analyzed for $\mathrm{Cl}^{-}$and $\mathrm{Na}^{+}$concentrations. Chloride was deter- mined by potentiometric titration with $\mathrm{AgNO}_{3}$ (Johnson et al., 1958). Sodium was measured by emission spectrophotometry of a 2 nitric : 1 perchloric digestion extract.

The model proposed by van Genuchten (1983) for evaluating crop salt tolerance was used to determine the response curves of LDW and SDW to the EC of the substrate or to leaf $\mathrm{Cl}^{-}$and $\mathrm{Na}^{+}$concentrations. The replacement of substrate $\mathrm{EC}$ by $\mathrm{Cl}^{-}$ or $\mathrm{Na}^{+}$leaf concentrations was supported by the linear relationship between substrate $\mathrm{Cl}^{-}$and $\mathrm{Na}^{+}$concentrations and the absorption of these ions by the plant, as shown by Rush and Epstein (1976) and by us (data not shown).

The model is given by:

$$
Y=\mid \begin{array}{lr}
Y_{m} & 0 E C \leq E C_{t} \\
Y_{m}-Y_{m} \cdot s\left(E C-E C_{t}\right) & E C_{t}<E C \leq E C_{o} \\
0 & E C>E C_{o}
\end{array}
$$

where $\mathrm{Y}=$ absolute yield, $\mathrm{Y}_{\mathrm{m}}=$ theoretical maximum yield, $\mathrm{Y}_{\mathrm{m}} \cdot \mathrm{S}=$ slope (yield decrease per unit salinity increase), $\mathrm{EC}=$ electrical conductivity of root medium solution, $\mathrm{EC}_{\mathrm{t}}=\mathrm{EC}$ threshold (maximum salinity without yield reduction), and $\mathrm{EC}_{\mathrm{o}}$ = EC at which yield would reach zero. The computer "SALT" program (van Genuchten, 1983) was used to determine simultaneously $\mathrm{Y}_{\mathrm{m}}$, slope, $\mathrm{EC}_{\mathrm{t}}$, and $\mathrm{EC}_{\mathrm{o}}$. We selected option 5 , as it allows no a priori fixing of any condition (neither the points to the left nor to the right of threshold, nor maximum yield) and simultaneously computes the parameters using Marquardt's approximation algorithm (Marquardt, 1963). As a criterion for goodness-of-fit of the data to the theoretical model, the coeffi- 
cient of determination $\left(R^{2}\right)$ was used. Absolute values must be used for this model. The response functions were determined for the three blocks together and for each block individually to verify the influence of blocks. For each genotype, standard deviations of the $\mathrm{Y}_{\mathrm{m}}$ and slope calculated values for each block were determined. Analysis of variance was performed for $\mathrm{EC}_{\mathrm{o}}$ and leaf $\mathrm{Cl}\left(\mathrm{Cl}_{\mathrm{o}}\right)$ and $\mathrm{Na}\left(\mathrm{Na}_{\mathrm{o}}\right)$ concentrations, at which LDW and SDW would reach zero. Significant differences among genotypes were determined by the LSD values.

\section{Results}

Salinity threshold and slope values. Salinity reduced LDW and SDW for all genotypes of the four Lycopersicon species, and the data fit the model well. Most $R^{2}$ values were higher than 0.70 (Fig. 1).

Among the five accessions of $L$. pimpinellifolium, $\mathrm{Y}_{\mathrm{m}}$ ranged from 201 to $351 \mathrm{~g}$ for LDW and from 138 to $336 \mathrm{~g}$ for SDW (Fig. 1). Both dry weights decreased with increasing salinity. For this reason, their tolerance cannot be assessed on the basis of a salinity threshold. Based on slope values, PE-2 would be the most salt-tolerant genotype, as it had the lowest slope value, PE-13 was the second most salt-tolerant of the $L$. pimpinellifolium genotypes, followed by PE-15, PE-14, and PE-8, which was the most salt-sensitive. In relation to the control plants, LDW and SDW of PE-2 were reduced by $30 \%$ and $37 \%$, respectively, at the highest salinity level, while PE- 8 had a decrease of $85 \%$ and $75 \%$. PE-14 was the only genotype of $L$. pimpinellifolium showing significant differences in slope between LDW and SDW. LDW salt tolerance of PE-14 was similar to that of PE-8, but SDW salt tolerance of PE-14 was higher than PE-8 and similar to PE-15.

Some accessions of $L$. peruvianum had a low threshold value for SDW, but all values were $<0.28 \mathrm{~S} \cdot \mathrm{m}^{-1}$ (Fig. 2). Thus, the threshold salinity cannot be used to evaluate the salinity tolerance of the L. peruvianum genotypes. Based on slope, PE-16 was the most salt-tolerant. This genotype, which had the lowest LDW and SDW values at low $\mathrm{NaCl}$ concentrations, was one of the highest yielding at the highest salinity level tested, and its LDW and SDW reductions compared to the control plants were of $63 \%$ and $73 \%$, respectively. PI-40 was the second most salt-

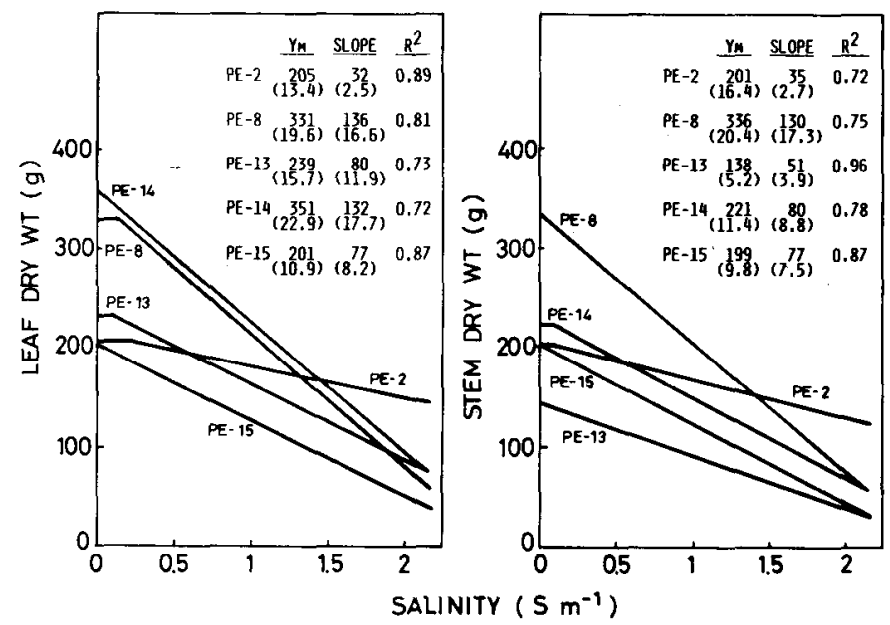

Fig. 1. Vegetative yield-electrical conductivity response curves of five genotypes from $L$. pimpinellifolium. $\mathrm{Y}_{\mathrm{m}}=$ maximum theoretical dry weight. Slope $=$ dry weight reduction per unit salinity increase. $R^{2}=$ cocfficicnt of detcrmination. Numbers in parentheses are standard deviations of the respective means.

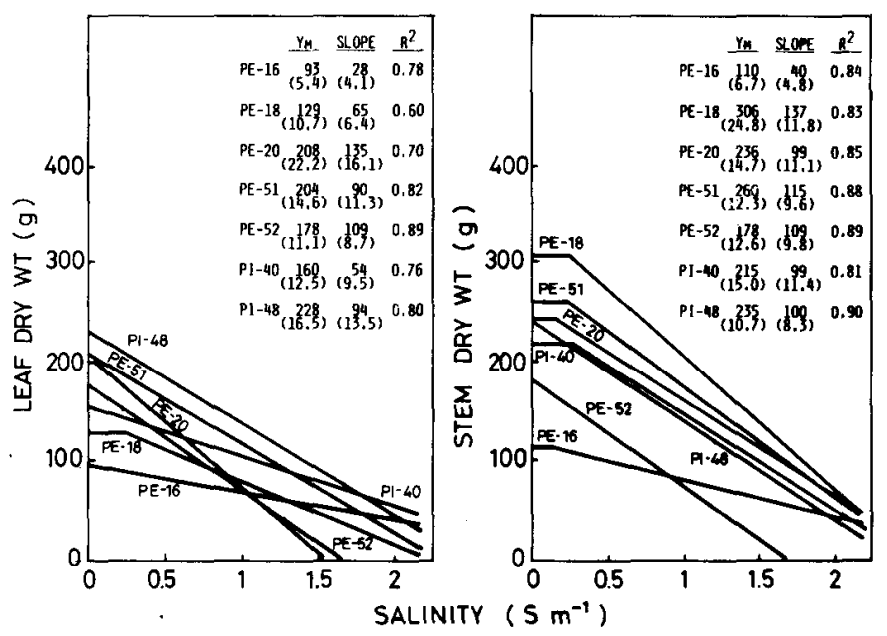

Fig. 2. Vegetative yield-electrical conductivity response curves of seven genotypes from $L$. peruvianum. $\mathrm{Y}_{\mathrm{m}}=$ maximum theoretical dry weight. Slope $=$ dry weight reduction per unit salinity increase. $R^{2}=$ coefficient of determination. Numbers in parentheses are standard deviations of the respective means.
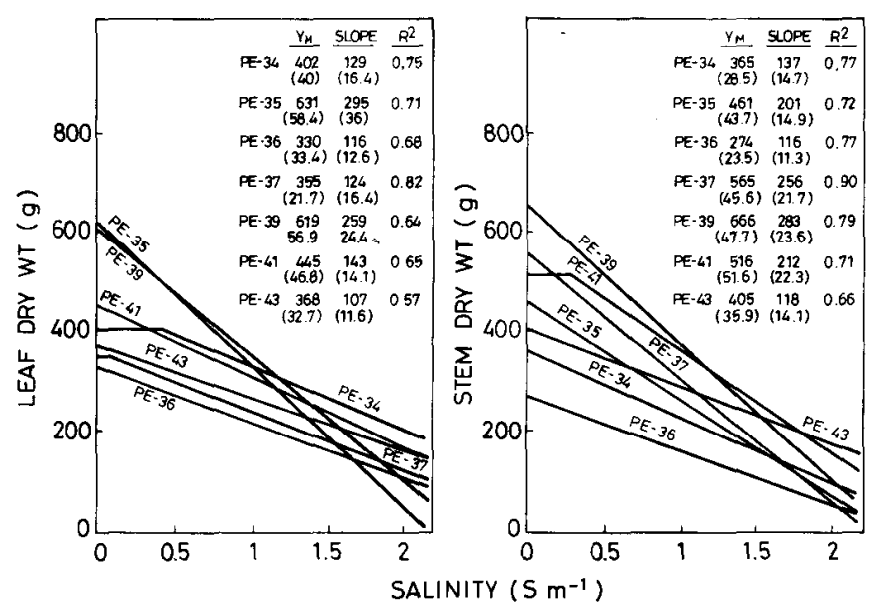

Fig. 3. Vegetative yield-electrical conductivity response curves of seven genotypes from $L$. hirsutum. $\mathrm{Y}_{\mathrm{m}}=$ maximum theoretical dry weight. Slope $=$ dry weight reduction per unit salinity increase. $R^{2}$ $=$ coefficient of determination. Numbers in parentheses are standard deviations of the respective means.

tolerant of the L. peruvianum genotypes. PE-52 had zero dry matter yield at $1.7 \mathrm{~S} \cdot \mathrm{m}^{-1}$ and was the least salt-tolerant accession. PE-20 and PE-18 changed their behavior when LDW and SDW were considered. PE-20 had the steepest slope for LDW and an intermediate one for SDW. PE-18 slope was intermediate for LDW and highest for SDW.

Dry weight yields of leaves and stems for L. hirsutum entries were from 274 to $666 \mathrm{~g}$ (Fig. 3). L. hirsutum had the highest yield among the four species groups. However, some of the entries would have zero dry matter yield at $2.15 \mathrm{~S} \cdot \mathrm{m}^{-1}$ salinity level. Based on slope values, PE-35 and PE-39 were the most salt-sensitive of the L. hirsutum genotypes (295 and $259 \mathrm{~g} \mathrm{LDW}$ decrease, respectively, per unit of increase of the substrate EC). The entries PE-34, PE-36, and PE-43 had the shallowest slope, around $115 \mathrm{~g}$ yield decrease per unit increase in salinity level. PE-37 was one of the best genotypes when LDW was considered and it had one of the steepest slopes according to stem dry 


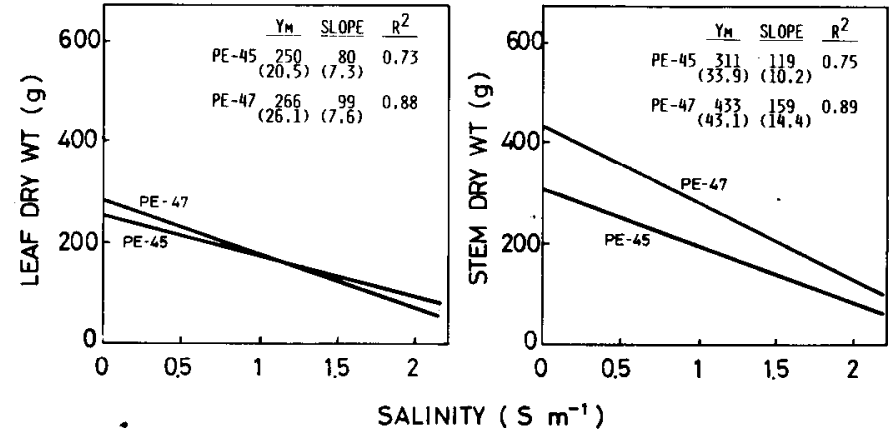

Fig. 4. Vegetative yield-electrical conductivity response curves of two genotypes from $L$. pennellii. $Y_{\mathrm{m}}=$ maximum theoretical dry weight. Slope $=$ dry weight reduction per unit salinity increase. $R^{2}$ $=$ coefficient of determination. Numbers in parentheses are standard deviations of the respective means.

weight, but this was the only $L$. hirsutum accession changing its behavior.

The two entries of L. pennellii were not significantly different in salinity tolerance (Fig. 4). The slopes were of the same order as those of the most salt-tolerant $L$. hirsutum genotypes although their maximum LDWs were lower.

$E C_{o}, \mathrm{Cl}_{o}$, and $\mathrm{Na}_{o}$ values. The salinity beyond which the yield becomes zero, $\mathrm{EC}_{0}$, was calculated according to the equation: $\mathrm{EC}_{\mathrm{o}}=\mathrm{EC}_{\mathrm{t}}+\mathrm{Y}_{\mathrm{m}} \cdot \mathrm{slope}^{-1}$.

$\mathrm{EC}_{\mathrm{o}}$ is defined by both slope and threshold parameters; consequently, this parameter could be more useful for evaluating the salinity response of genotypes. According to $\mathrm{EC}_{0}$ values determined by the function vegetative yield vs. EC, PE-2 was the most salt-tolerant genotype of $L$. pimpinellifolium, PE-16 and PI-40 of $L$. peruvianum, and PE-34 and PE-43 of L. hirsutum (Table 1). These results were similar to the ones obtained from the slope values. Thus, the slope values had more influence on $\mathrm{EC}_{\mathrm{o}}$ than $\mathrm{Y}_{\mathrm{m}}$ and threshold values.

The model not only was applied according to the substrate salinity level, but also according to $\mathrm{Cl}^{-}$and $\mathrm{Na}^{+}$leaf concentrations. $\mathrm{Cl}_{\mathrm{o}}$ and $\mathrm{Na}_{\mathrm{o}}$ parameters were determined for all the genotypes whose data fit the model. $\mathrm{Cl}_{\mathrm{o}}$ and $\mathrm{Na}_{\mathrm{o}}$ gave almost identical results because both resulted in three groups in $L$. pimpinellifolium: PE-2, PE-8 and PE-14, PE-13 and PE-15 (Table 1). Results of $\mathrm{Cl}_{0}$ and $\mathrm{Na}_{0}$ also coincide for $L$. peruvianum and $L$. hirsutum. When the highest values are considered, PI40 and PI-48 were the most salt-tolerant $L$. peruvianum genotypes and PE-34 and PE-43 were for $L$. hirsutum genotypes.

The most important difference between the calculated $\mathrm{EC}_{\mathrm{o}}$ values and those of $\mathrm{Cl}_{0}$ and $\mathrm{Na}_{o}$ was that PE-16 did not accumulate as much $\mathrm{Cl}^{-}$and $\mathrm{Na}^{+}$in the leaves and stems as did most of the other genotypes.

$\mathrm{Na}_{0}: \mathrm{Cl}_{\mathrm{o}}$ ratios were lower in $L$. peruvianum than in other species, with the exception of PI-40 and PI-48, which belong to $L$. peruvianum glandulosum.

Considering the four species together, PE-2, PE-43, and PE16 had the highest $\mathrm{EC}_{0}$ values for LDW and SDW; PE-2, PE45, PE-34, and PI-40 were the accessions with highest $\mathrm{Cl}_{0}$ values for LDW; and PE-2, PE-45, PE-34, PE-51, and PE-43 for SDW. The most tolerant genotypes based on $\mathrm{Na}_{0}$ for LDW and SDW were PE-2, PE-45, PE-34, PI-40, and PE-14.

\section{Discussion}

The wild relatives of the cultivated tomato represent a potential source of useful genetic variation (Rick, 1988). Variation for salt tolerance has been previously demonstrated within $L$. peruvianum and L. pennellii (Dehan and Tal, 1978; Tal, 1971; Tal and Shannon, 1983). However, the L. pimpinellifolium and $L$. hirsutum species have been the least tested in plant breeding. Jones (1986) included two entries from $L$. pimpinellifolium and one from $L$. hirsutum when assessing the salinity tolerance of different tomato species at the germination stage. In this work, besides $L$. peruvianum and $L$. pennellii, L. pimpinellifolium and $L$. hirsutum also were tested for salinity tolerance.

In the four wild species of Lycopersicon, even the lowest salt concentration decreased the LDW and SDW. For this reason, their tolerance cannot be assessed on the basis of the salinity threshold, but on the basis of the slope of the-function vegetative yield vs. EC.

Genotype salt tolerance evaluation by slope and $\mathrm{EC}_{\mathrm{o}}$ gave similar results using either LDW and SDW, except for three (PE-18, PE-20 in L. peruvianum, and PE-37 in L. hirsutum) of the 21 genotypes. Therefore, either LDW and SDW could be used alone without great loss of accuracy in Lycopersicon salttolerance evaluation.

Although slope and $\mathrm{EC}_{\mathrm{o}}$ provide similar salt-tolerance evaluations in this work, their meanings are rather different. $\mathrm{EC}_{\mathrm{o}}$ is determined by $\mathrm{Y}_{\mathrm{m}}$, threshold, and the slope. Thus, $\mathrm{EC}_{\mathrm{o}}$ should be an important parameter for evaluating the salinity tolerance of tomato cultivars that could be used directly by growers, because $\mathrm{EC}_{0}$ not only included the salt tolerance parameters but also $Y_{m}$. When wild species are evaluated to determine which genotypes could be used for improving salt tolerance of commercial L. esculentum cultivars, the slope and/or the threshold provide more information than $Y_{m}$ for the evaluation of wild accessions.

Based on slope and $\mathrm{EC}_{0}$, almost all of the most salt-tolerant accessions, PE-2, PE-45, PE-34, and PE-43, had the highest $\mathrm{Cl}_{\mathrm{o}}$ and $\mathrm{Na}_{0}$ values. This fact suggests that the predominant salttolerance mechanism involves ion accumulation. Our interpretation of the data suggests that PE-2, PE-45, PE-34, and PE-43 accessions were salt-tolerant, not because they are more capable of restricting $\mathrm{Cl}^{-}$and $\mathrm{Na}^{+}$uptake at high $\mathrm{NaCl}$ levels than other accessions, but because they have a superior ability to tolerate high levels of $\mathrm{Cl}^{-}$and $\mathrm{Na}^{+}$in their tissues (Bernstein, 1963). It is also plausible that high ion accumulation is a necessary consequence of the ability to survive. Chloride and $\mathrm{Na}^{+}$accumulation in wild species have been reported by other researchers (Dehan and Tal, 1978; Phills et al., 1979; Tal and Shannon, 1983), suggesting that $\mathrm{Na}^{+}$leaf concentrations could be used as a key characteristic in evaluation of germplasm for salt-tolerance breeding programs of cultivated tomato (Rush and Epstein, 1981). However, ion concentrations in different leaves may be quite different and this may contribute to salt tolerance. Thus, the $\mathrm{Cl}^{-}$and $\mathrm{Na}^{+}$accumulation in cultivated and wild tomato species was higher in mature leaves than in developing leaves (Shannon et al., 1987). However, other studies showed that the ability to regulate $\mathrm{Na}^{+}$, rather than $\mathrm{Na}^{+}$ content per se, was closely correlated with salt tolerance (Sacher et al., 1983).

$\mathrm{Cl}_{\mathrm{o}}$ values were higher than $\mathrm{Na}_{0}$ values. The $\mathrm{Na}_{0}: \mathrm{Cl}_{0}$ relationship was between 0.5 and 0.6 for $L$. pimpinellifolium, $L$. hirsutum, and $L$. pennellii, but was lower for $L$. peruvianum. The different accumulation of $\mathrm{Cl}^{-}$and $\mathrm{Na}^{+}$in $L$. peruvianum in relation to other wild tomato species already had been observed (Shannon et al., 1987). This differential accumulation suggests that there are differences among species in $\mathrm{Na}^{+}$uptake with increasing salinity. The difference may be directly related 
either to the toxicities of these ions or to their roles in osmotic adjustment. Slatyer (1961) suggested that $\mathrm{Na}^{+}$accumulation determines reduction in development more than $\mathrm{Cl}^{-}$.

PE-2 from $L$. pimpinellifolium seems to be a salt-tolerant accession. Since crosses between $L$. pimpinellifolium and $L$. esculentum (the tomato of commerce) are easily made and are closely related genetically (Warnock, 1988), it should, therefore, be rewarding to exploit this source of salt tolerance.

\section{Literature Cited}

Anastasio, G., M.S. Cataká, G. Palomares, J. Costa, and F. Nuez. 1987. An assessment of the salt tolerance in several tomato genotypes. 10th Proc. Meeting Tomato Working Group Eucarpia. Salerno, Italy, 2-6 Sept. 1987. p. 57-61.

Bernstein, L. 1963. Osmotic adjustment of plants to saline media. II. Dinamic phase. Amer. J. Bot. 50:360-370.

Bernstein, L., L.E. Francois, and R.A. Clark. 1974. Interactive effects of salinity and fertility on yields of grain and vegetables. Agron. J. 66:412-421.

Bingham, F.T., J.E. Strong, J.D. Rhoades, and R. Keren. 1985. An application of the Maas-Hoffman salinity response model for boron toxicity. Soil Sci. Soc. Amer. J. 49:672-674.

Dehan, K. and M. Tal. 1978. Salt tolerance in the wild relatives of the cultivated tomato responses of Solanum pennellii to high salinity. Irr. Sci. 1:71-76.

Feinerman, E., D. Yaron, and H. Bielorai. 1982. Linear crop response functions to salinity with a threshold salinity level. Water Resource Res. 18:101-106.

Johnson, C.M., R.P. Huston, and P.C. Ozanne. 1958. Measurement of microgram amounts of chlorine in plant materials. Agr. Food Chem. 6:114-118.

Jones, R.A. 1986. High salt tolerance potential in Lycopersicon species during germination. Euphytica 35:575-582.

Lyon, C.B. 1941. Responses of two species of tomatoes and the Fl generation to sodium sulphate in the nutrient medium. Bot. Gaz. 103:107-122.
Maas, V. and G.J. Hoffman. 1977. Crop salt tolerance. Current assessment. J. Irr. Drainage Div. 103:116-134.

Marquardt, D.W. 1963. An algorithm for least squares estimation of non-linear parameters. J. Soc. Ind. Applied Math. 11:431-441.

Phills, B.R., N.H. Perck, G.E. MacDonald, and R.W. Robinson. 1979. Differential response of Lycopersicon and Solanum species to salinity. J. Amer. Soc. Hort. Sci. 104:349-352.

Rick, C.M. 1988. Molecular marker as aids for germplasm management and use in Lycopersicon. HortScience 23:55-57.

Rush, D.W. and E. Epstein. 1976. Genotypic responses to salinity. Differences between salt sensitive and salt tolerant genotypes of the tomato. Plant Physiol. 57:162-166

Rush, D.W. and E. Epstein. 1981. Comparative studies on the sodium, potassium and chloride relations of a wild halophytic and a domestic salt-sensitive tomato species. Plant Physiol. 68:1308-1313.

Sacher, R.F., R.C. Staples, and R.W. Robinson. 1983. Ion regulation and response of tomato to sodium chloride: A homeostatic system. J. Amer. Soc. Hort. Sci. 108:566-569.

Shannon, M.C., J.W. Gronwald, and M. Tal. 1987. Effects of salinity on growth and accumulation of organic and inorganic ions in cultivated and wild tomato species. J. Amer. Soc. Hort. Sci. 112:416423.

Slatyer, R.O. 1961. Effects of several osmotic substrates on the water relations of tomato. Austral. J. Biol. Sci. 14:519-540.

Tal, M. 1971. Salt tolerance in the wild relatives of the cultivated tomato: Response of Lycopersicon esculentum, L. peruvianum, and L. esculentum minor to sodium chloride solutions. Austral. J. Agr. Res. 22:631-638,

Tal, M. and M.C. Shannon. 1983. Salt tolerance in the wild relatives of the cultivated tomato: Response of Lycopersicon esculentum, $L$. cheesmanii, L. peruvianum, Solanum pennellii and Fl hybrids to high salinity. Austral. J. Plant Physiol. 10:109-117.

van Genuchten, M.Th. 1983, A general optimization method for analyzing crop salt tolerance data: Model description and user's manual. U.S. Dept. Agr., Agr. Res. Serv., U.S. Salinity Laboratory. Res. Rpt. 120. U.S. Government Printing Office, Washington, D.C.

Warnock, S.J. 1988. A review of taxonomy and phylogeny of the genus Lycopersicon. HortScience 23:669-673. 